\title{
Paradoxical Features of Primary Shear Fractures and General Faults
}

\author{
B.G. Tarasov University of Western Australia, Australia \\ M.F. Randolph University of Western Australia, Australia
}

\begin{abstract}
This paper shows that hard rocks exhibit specific properties at high confining pressure that distinguish them markedly from common rock behaviour: they become extremely brittle and lose shear resistance within a certain range of shear rupture displacement. The combination of these two features results in increasing instability with depth and makes rupture abnormally violent, both of which are well established experimentally from studies of earthquakes and rock bursts at high stress levels. The behaviour is caused by the intrinsic nature of the fault structure, which is an echelon of blocks operating as hinges, essentially eliminating friction at high confining pressure of a certain displacement range. The paper demonstrates that, while the same structure may be found at different scale in primary fractures and general faults, significantly different mechanisms are responsible for the formation of the structure in each case. A new approach is proposed for understanding fault segmentation and the role of junctions in fault propagation. It is argued that segmentation is a result of advanced triggering of new fractures that propagate both towards the current fracture and in the opposite direction. This mechanism triples the fault propagation speed. Junctions formed at the meeting of the approaching segments help to accommodate the fault displacement and can significantly decrease the fault strength - thus contradicting the general belief that junctions represent strength barriers impeding the fault motion. The improved understanding of the fracture process is important for better prediction and mitigation of dynamic events such as earthquakes and rock bursts.
\end{abstract}

\section{Introduction}

Shear is the only form of rock mass rupture at depth that leads to large scale deformations accompanied by large energy release. Spontaneous developments of new ruptures and reactivation of old ones cause earthquakes and rockbursts, but the detailed mechanics of shear rupture development is still enigmatic in many respects. This paper discusses a number of aspects of shear rupture of pristine hard rocks that do not have unambiguous explanations at present, and describes new mechanisms for primary fractures and general faults that fit observed behaviour.

Paradoxical aspects of spontaneous shear rupture development in hard rocks at great depth (high confining pressure), which contradict commonly accepted rock properties, include:

- Abnormally intense rupture violence and absence of temperature increase in the rupture zone, which together imply very low friction despite the high normal stresses in faults at great depth.

- Increase in shear rupture activity and violence with depth, implying an increase in rock brittleness with rising confining pressure, in contrast to the commonly accepted more ductile behaviour.

- Abnormally low shear resistance of some existing faults, contradicting traditional views of residual rock strength based upon laboratory experiments.

These questions have been studied extensively over a number of decades (e.g. McKenzie and Brune, 1972; Sibson, 1980; Hickman, 1991; Chester at al., 1993; Ortlepp, 1997; Scholz, 2002; Tarasov and Dyskin 2005).

Additional aspects concern the nature of shear rupture propagation in pristine rocks, with no consensus of opinion reached regarding the physical explanation for the following features of faults (Das, 1985; Domovska and Rice, 1986; Rice, 2001; Scholz, 2002; Rosakis, 2002):

- Fault segmentation and linkage of segments.

- Intersonic speed of fracture propagation. 
- Critical fracture length associated with initiation of the instability.

- Curvilinear fracture traces.

The present paper proposes a new approach to resolve these paradoxes, based on a 'frictionless shear' concept (Tarasov and Randolph, 2007). The key idea of the concept is that a specific fault structure is developed in hard rocks shearing at high confining pressure; the structure largely eliminates friction within the fault over a finite displacement range.

\section{Frictionless shear}

\subsection{Post-peak behaviour of hard rocks at high confining pressure}

Hard rocks of interest here are mainly magmatic and metamorphic rocks with homogeneous and fine-grained structure, e.g. granite, basalt, quartzite, diabase, dolerite etc. Recently it was shown that the first three paradoxes described in the introduction can be explained by specific post-peak properties that hard rocks exhibit at high confining pressure (Tarasov and Randolph, 2007). Figure 1 illustrates schematically the difference in the post-peak behaviour of hard rocks failed at high confining pressure in accordance with commonly assumed post-peak residual behaviour (Figure 1a) and the new observations from experimental data (Figure 1b).
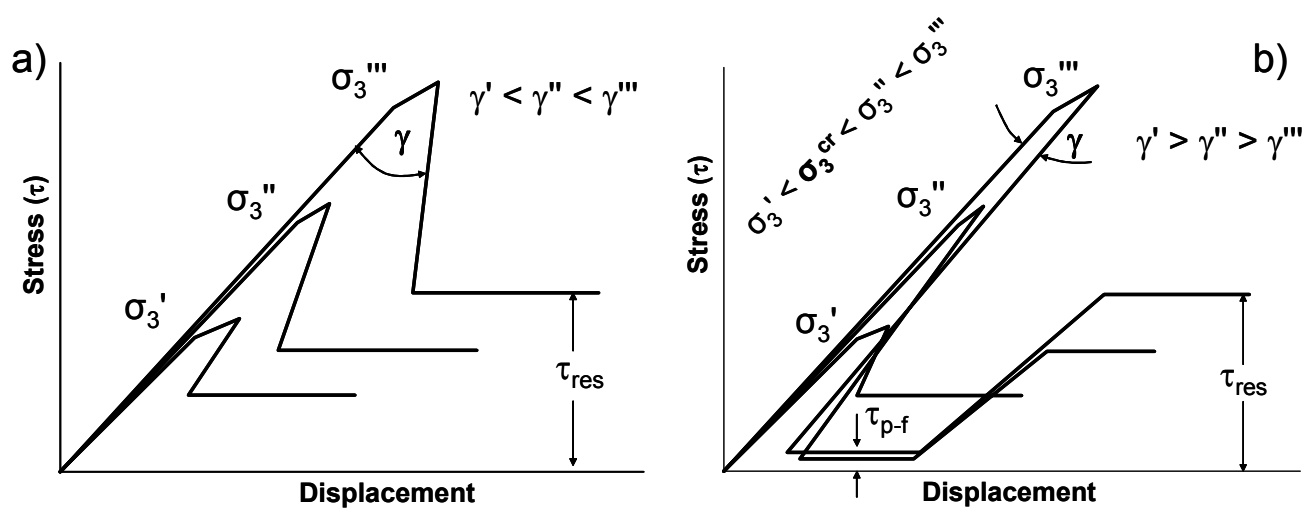

Figure 1 Behaviour of hard rocks at different levels of confining pressure in accordance with a) common knowledge and b) new concept

The new data showed that at high confining pressure (exceeding some critical level $\sigma_{3}>\sigma_{3}{ }^{\text {cr }}$ ) hard rocks change their behaviour drastically. They become very brittle with brittleness (characterised here by angle $\gamma$ ) increasing with $\sigma_{3}$.The immediate post-failure resistance $\left(\tau_{\mathrm{p}-\mathrm{f}}\right)$ becomes very low and normal frictional residual strength $\left(\tau_{\text {res }}\right)$ is only mobilised after finite fault displacement.

Such unusual hard rock behaviour was not detected previously because virtually all experimental studies of post-peak properties have been conducted at relatively low confining pressure $\left(0 \leq \sigma_{3} \leq \sigma_{3}{ }^{\text {cr }}\right)$. Within this range the rock behaviour is normal, allowing the post-peak failure to be controlled by suitably stiff loading apparatus. At higher $\sigma_{3}$, where rocks exhibit increasingly brittle behaviour, the maintenance of stability becomes impossible. A new method was developed by the authors to study post-peak properties during unavoidable spontaneous failure at high $\sigma_{3}$. The mechanism that governs the post-peak rock behaviour of hard rocks under these conditions is described below.

\subsection{Frictionless fault structure}

The intrinsic nature of shear fractures formed in rock-like heterogeneous materials is represented by a specific structure, comprising an echelon of blocks (slabs, beams) separated by tensile cracks (see example later in Figure 3b). The fault displacement along such structure is accompanied by rotation, buckling and failure of the blocks. Existing models (e.g. Peng and Johnson, 1972; Ashby and Sammis, 1990; Lockner et al., 1991; King and Sammis, 1992; Reches and Lockner, 1994; Mandel, 2000) consider this process for all 
kind of rocks and stress conditions as a fully frictional process where the fault development is accompanied by a gradual substitution of cohesive material strength by frictional resistance. The material strength decreases monotonically, reaching a minimum value corresponding to the residual frictional strength $\tau_{\text {res }}$ once failure is complete (see Figure 1a). Increase in confining pressure results in higher post-fracture resistance $\tau_{\text {res }}$ and less brittle response (increase in angle $\gamma$ ).

This assumption, however, is not correct for hard rocks failed at high confining pressures $\left(\sigma_{3}>\sigma_{3}{ }^{c r}\right)$. Under these conditions the formation of long tensile cracks is suppressed, so that the fault structure comprises blocks that are short enough to withstand rotation without failure. This is possible in hard rocks only due to their very high strength. In this situation the blocks operate as hinges and friction between them essentially disappears. Figure 2a shows schematically a fragment of such fault at four stages of its displacement.

(i)

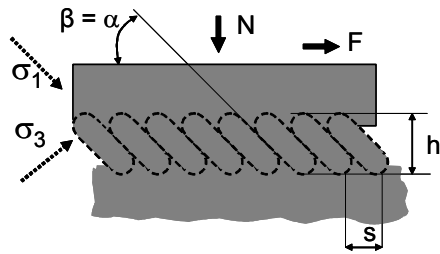

a)

(iii)

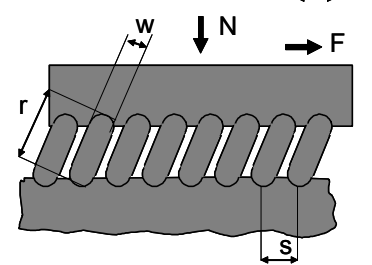

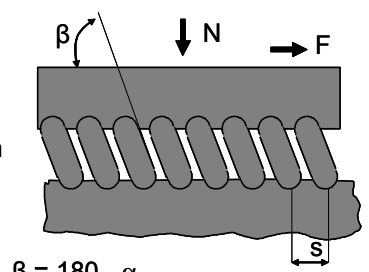

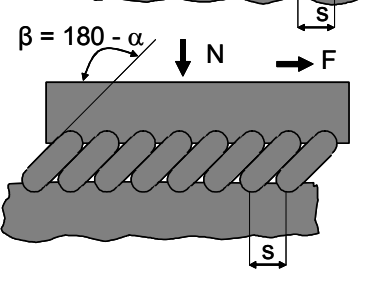

(ii)

b)

$\mathrm{F}^{\prime}$

(iv)

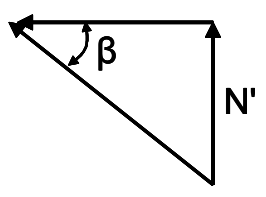

c)

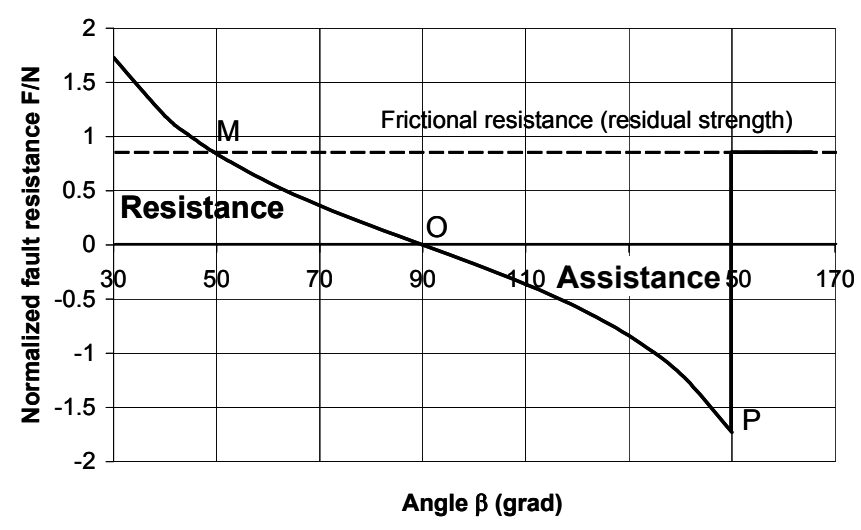

Figure 2 Idealised concept of the frictionless fault displacement

The fault resistance to shear in this case is a function of the block orientation to the fault axis (angle $\beta$ ). The interrelation between fault resistance $F^{\prime}$, normal reactive force $N^{\prime}$ and angle $\beta$ is shown in Figure $2 \mathrm{~b}$. Figure 2c demonstrates the variation of the normalised fault resistance $\left(F^{\prime} / N^{\prime}\right)$ versus angle $\beta$. The range of angle $\beta$ variation here is $\alpha \leq \beta \leq 180^{\circ}-\alpha$, where $\alpha=30^{\circ}$ is the angle of initial orientation of the tensile cracks in respect to the fault axis (as typically found for hard rocks). A dotted line on the graph represents the level of the normalised residual strength, corresponding to a coefficient of friction of 0.8 (typical for hard rocks).

The graph shows that the fault resistance decreases with displacement, continuing past the residual frictional resistance (at point $\mathrm{M}$ ) and reaches zero resistance at point $\mathrm{O}$, where $\beta=90^{\circ}$. At $\beta>90^{\circ}$ the fault resistance becomes negative which means that at this condition the block structure under the effect of the normal force $N$ creates an active force assisting the fault displacement. The greater is the angle $\beta$ the greater is the active force. Two parts of the graph $F^{\prime} / N^{\prime}$ versus $\beta$ lying above and below the horizontal axis indicate that the work done by the reactive $\left(F^{\prime}=F_{R}^{\prime}\right)$ and active $\left(F^{\prime}=F_{A}^{\prime}\right)$ forces within the total range of block rotation is equal to zero. When the blocks have completed their rotation at point $\mathrm{P}$ the friction within the fault structure is restored sharply and further displacement along the fault occurs in accordance with the friction law. 


\subsection{Manifestations of the frictionless mechanism}

The model shows that the block structure of shear fractures can create active forces under the effect of normal stress, which makes the fault resistance negative over a certain displacement. It should be emphasised that in practice the minimum post-failure resistance $\tau_{\mathrm{p}-\mathrm{f}}$ (see Figure $1 \mathrm{~b}$ ) of real faults stays greater then zero (but significantly lower than the residual strength $\tau_{\text {res }}$ ). This is due to highly non-uniform activation of the frictionless mechanism along the fault, as will be discussed below. At this stage, though, we can link the features mentioned in the Introduction to different manifestations of the frictionless mechanism:

- Abnormal rupture violence is caused by significantly greater energy released at spontaneous failure in accordance with the post-peak behaviour in Figure 1b compared with Figure 1a.

- Low post-failure resistance $\tau_{\mathrm{p}-\mathrm{f}}$ and the lack of dependence on confining pressure (within some range of $\sigma_{3}$ ) cause the abnormal increase in the fracture violence with depth.

- Increase in shear rupture activity with depth can be caused by increase in rock brittleness. The greater brittleness with increasing $\sigma_{3}$ (or depth) is explained as follows. The increase in $\sigma_{3}$ decreases the length of tensile cracks and the blocks located between them within the fault structure. The shorter are the blocks, the smaller is the fault displacement required to decrease the fault resistance to a given value.

- The low strength of some existing faults may result from a fault structure condition corresponding to the post-failure zone characterised by low shear strength $\tau_{\text {p-f. }}$

- The sharp restoration of resistance after completion of the block rotation resulted in intense postrupture shock waves in laboratory experiments.

More detailed discussion of these questions is given by Tarasov and Randolph (2007).

\section{Shear fracture nucleation and propagation in hard rocks}

\subsection{Modern understanding}

Shear fractures (faults) are very complicated mechanical formations with a specific structure. Properties and behaviour of faults are determined by internal mechanisms governing the structure development and external mechanisms of the fault interaction with the surrounding medium. These two types of mechanisms are interrelated and should be taken into account for full understanding of the shear rupture phenomenon. Models reflecting the external mechanisms normally consider faults as a structureless formation or as a mathematical line along which mode-II cracks may propagate dynamically. This type of models has been developed extensively, resulting in significant progress in the shear rupture understanding (Das, 1985; Domowska and Rice, 1986; Broberg, 1999; Rice, 2001; Scholz, 2002; Freund, 1990; Rosakis, 2002). However, neglect of the internal mechanism in these models can sometimes lead to incorrect conclusions. For instance, the natural tendency of faults to exhibit segmentation, wavy fault paths and intense microcracking should significantly decrease the maximum achievable rupture speed in real faults compared with theoretical predictions made for idealised models.

An important breakthrough in understanding internal mechanisms responsible for development of the fault structure was made quite recently when acoustic emission technology and stiff servo-controlled loading systems became available (Moore et al., 1990; Lockner et al., 1991; Reches and Lockner, 1994). In accordance with these observations the mechanics of shear rupture nucleation and propagation is as follows. In hard rocks a fault nucleates by local interaction between a few micro-cracks and propagates into the unfaulted regions by inducing new micro-crack growth at its tip; this eventually forms a specific fault structure - an echelon of blocks (slabs, beams) separated by tensile cracks. The fault displacement along such a structure is accompanied by rotation, buckling and failure of the blocks. Three characteristic zones in the propagating shear fracture were distinguished: i) a process zone that lies at the head of the fracture, where an echelon of micro-cracks develops, oriented parallel to the maximum compressive stress direction; ii) a core zone consisting of comminuted rock material, which forms immediately after the fault front has passed through; iii) a damage zone, which comprises a broader volume of more distributed irreversible deformation around the fault. 
However, many questions associated with the fault structure development are still unclear. In particular, questions concerning such features as: fault segmentation and linkage between segments; curvilinear traces of shear fractures; length of the process zone; critical fracture length required for instability; intersonic speed of fracture propagation. Below we present a new approach to resolve these questions based on the frictionless concept. In our discussion we will use the following simple classification of faults:

- Primary shear fractures - continuous thin ruptures with uniform structure (see Figure 3a).

- General faults - complex discontinuous systems comprising primary fractures, segments, overlap regions, junctions, and other geometrical complexities (see Figures $3 \mathrm{~b}$ and $3 \mathrm{c}$ ).

We will discuss first features of the development of primary fractures and then features of general faults. It will be shown that despite the similarity in the fault structure (rotating blocks), the mechanisms governing the development of these two forms of shear ruptures, as well as certain properties of them, are markedly different. This subject has been discussed earlier by Tarasov (2007).

a)

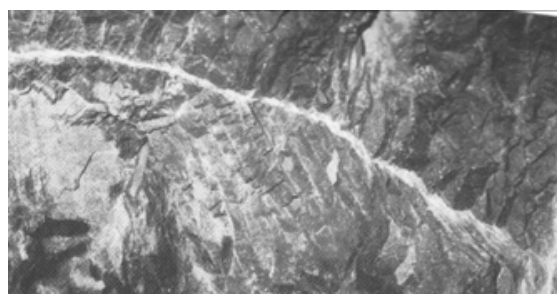

c)

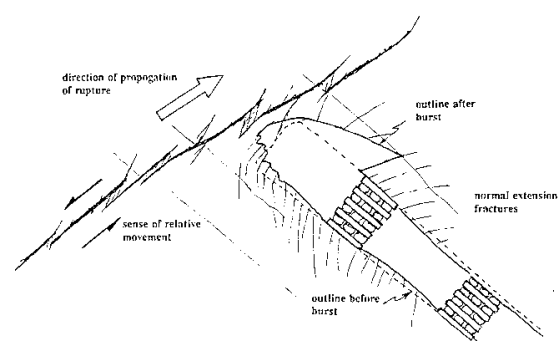

b)

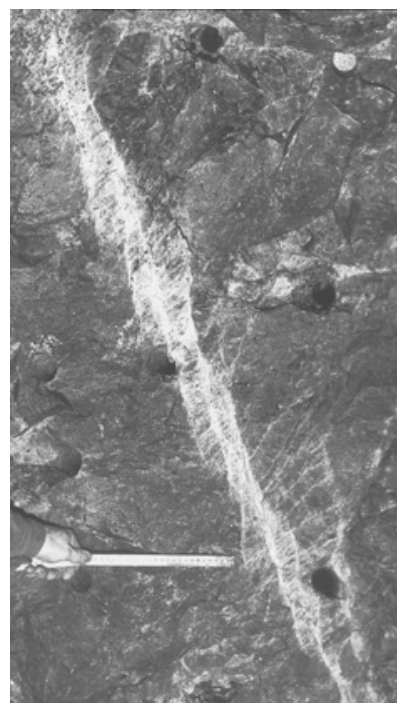

Figure 3 (a) Primary shear rupture and (b), (c) general faults (from Ortlepp, 1997)

\subsection{Primary shear fracture}

\subsubsection{Structure and propagation}

Primary fractures are normally thin and continuous formations with thickness ranging from fractions of a millimetre to a number of millimetres. Figure 4 illustrates new principles of the primary fracture development. Figure 4a represents a potential fault before the onset of its development. The eventual fault structure, comprising an echelon of blocks, does not exist initially, but will be created (activated) sequentially during the fault development. The eventual (potential) structure is shown here to illustrate that the rotation of activated blocks within the fault zone causes a transient increase in the fault thickness (in the vertical direction) but does not affect the material body along the fault (in the horizontal direction). Orientations of major $\sigma_{1}$, minor $\sigma_{3}$, shear $\tau$ and normal $\sigma_{\mathrm{n}}$ stresses applied to the material body are shown in the picture.

Five stages of the fault development are shown here. When shear stress approaches the level of ultimate shear strength the process of formation of the fault structure will start within the most suitable area of the material body determined by the local material strength and stress conditions. This process involves creation of tensile cracks and blocks between them and rotation of the blocks in response to the fault displacement. In accordance with the frictionless concept blocks representing the fault structure can rotate from the initial angle $\beta=\alpha$ up to the final angle $\beta=180^{\circ}-\alpha$, where $\alpha$ is the angle of initial orientation of the tensile cracks (and blocks) in respect to the fault axis. At the rotation a series of blocks eventually forms a fan-shaped structure at the head part of the propagating fracture (Figure 4f). The fan-shaped structure represents the process zone which is strictly determined in this model compared with existing models. The core zone in this 
case is represented by blocks that have completed their rotation. Within the core zone the friction is completely restored and the fault strength here is characterised by normal frictional resistance.
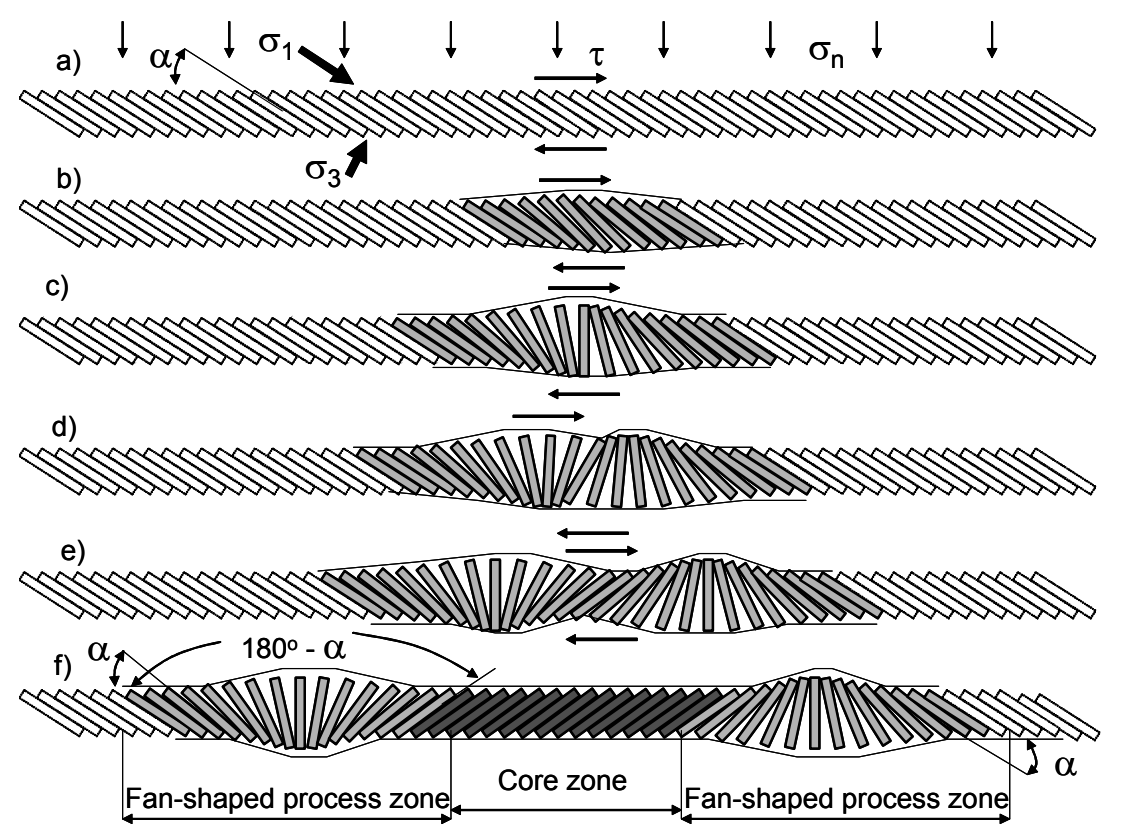

Figure 4 Idealised model of shear fracture propagation governed by the fan-shaped mechanism (from Tarasov, 2007)

a)

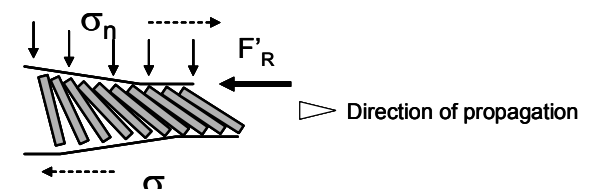

b)

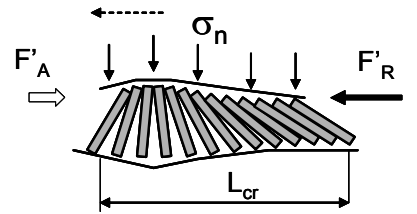

c)

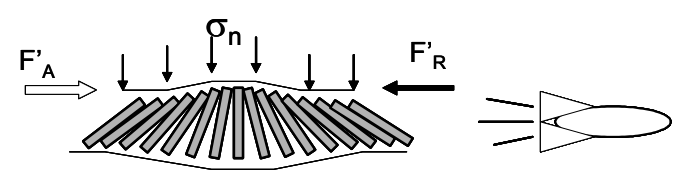

d)

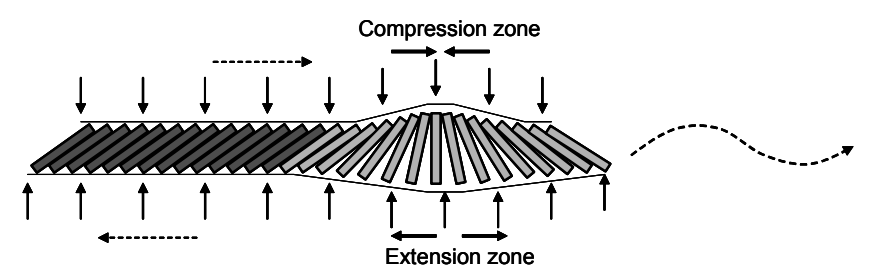

Figure 5 Fan-shaped structure as a self-equilibrating mechanism (from Tarasov, 2007)

\subsubsection{Fan-shaped self-equilibrating (compensating) mechanism}

The fan-shaped structure, the remarkable features of which are illustrated in Figure 5, is the key mechanism of dynamic fracture propagation. Figure 5a shows an opening fragment of the structure, with the fracture 
propagating from left to right and the shear direction indicated by dotted arrows. Rotating blocks of this fragment resist shearing due to the normal stress $\sigma_{\mathrm{n}}$. This resistance (the reactive force $\mathrm{F}^{\prime} \mathrm{R}$ ) can be very large at high confining pressure (or at great depth). The graph in Figure $2 \mathrm{c}$ shows that the normalised resistance to shear for a block structure oriented at angle $\alpha=30^{\circ}$ to the fault axis is initially double the residual strength. At smaller values of $\alpha$, which is possible for hard rocks, the resistance can be even greater.

A remarkable feature of the rotating blocks located in the second half of the fan structure (Figures $5 \mathrm{~b}$ and $5 \mathrm{c}$ ) is the creation of an active force $F^{\prime} A$ under the effect of the same normal stress $\sigma_{n}$. This force assists fracture propagation. At completion of the fan-structure formation (Figure 5c) the value of the active force becomes equal to the reactive force $\left(\mathrm{F}_{\mathrm{A}}^{\prime}=\mathrm{F}_{\mathrm{R}}^{\prime}\right)$. Thus the fan-shaped structure represents a self-equilibrating mechanism and can move as a wave, propagating the fracture under the action of relatively small shear stresses. Because the active force here is applied to the moving object (the fan-shaped head) this situation can be compared symbolically with the principle of a rocket engine.

The existence of the active force in the dynamically propagating fracture head can be treated as a velocityweakening effect, as adopted in many existing models of fracture propagation. The fan-shaped mechanism proposes a physical explanation of this phenomenon. It should be noted that in primary fractures the frictionless mechanism is activated within the fan-shaped head of the fracture only (in contrast with general faults discussed later). The core zone representing the majority of the fracture area exhibits normal residual frictional behaviour. After completion of the fracture propagation the structure of primary fractures is regular, continuous and with normal frictional resistance. We can suppose that the fan-shaped structure can form not only during fracture propagation in pristine heterogeneous materials (rocks) but also at stick-slip displacement along pre-existing fracture surfaces. The gouge material normally created within such fractures during stick-slip experiments can possibly represent elements of the fan-shaped structure.

A further important feature of the fan-shaped structure is the creation of compressive and tensile stresses within the opposite surfaces of the fracture (see Figure 5d), which can initiate tensile cracks within the extension surface of the fracture. The existence of a damaged zone along the extension fracture surface is well documented and may be explained by alternative mechanisms (Segal and Pollard, 1980; Moore and Lockner, 1995; Vermilye and Scholz, 1999; Rosakis, 2002). The fan-shaped structure represents an additional mechanism causing this known effect.

\subsubsection{Crack-like and pulse-like fracture propagation}

The fan-shaped mechanism can provide two known forms (crack-like and pulse-like) of fracture propagation. In the 'crack-like' models, fracture tip propagation is accompanied by displacement along the core zone (Das, 1985; Domowska and Rice, 1986; Rice, 2001). The shear resistance in the core zone of the fan-shaped model corresponds to fully restored residual friction, so that a corresponding shear stress must be applied to cause displacement along this zone. If this stress is not sufficient, the fan-shaped head will travel in the manner of 'pulse-like' models (Weertman, 1980; Heaton, 1990; Ben-Zion and Andrews, 1998). In that case the core zone behind the dynamically moving head stays stable and the total displacement along the fault is very small. The total displacement $d$ is then associated with block rotation within the head only, given by $d=2 h \tan \alpha$, where $h$ is the fault thickness and $\alpha$ is the initial angle of the block orientation (see Figure 2a). Hence, pulse-like fracture creation due to independent moving of the fan-shaped head (independent on the core zone), and resulting very small displacement of the shear fracture, can create very curvilinear traces similar to that shown in Figure 3a. The waviness of the fracture in this case is determined by non-uniformity in material strength and local stress conditions.

\subsubsection{Critical fracture length}

The nature of rock fracture development is that unstable propagation is foregone by a preceding phase of deformation. The correct understanding of the physical processes taking place at this phase is extremely important for predictive purposes. Knowing the physical mechanism it is possible, in particular, to determine with a higher degree of certainty the critical fracture length $\mathrm{L}_{\mathrm{cr}}$, which indicates the boundary between stable and unstable phases of the fracture process. Existing crack and friction-slider models do not consider the detailed physical mechanisms operating in the fracture zone and define the critical length independently of the fault structure (Andrews, 1976; Ida, 1982; Scholz, 2002). For example, in crack models $\mathrm{L}_{\mathrm{cr}}$ is determined 
from the assumption that a characteristic fracture energy per unit area is required for the crack to propagate. In the stick-slip models, rupture is assumed to occur when the stress on the fault reaches the static friction value and the condition for dynamic instability exists.

The fan-shaped concept provides better understanding of this phenomenon. According to the model the instability starts when the fan-shaped mechanism creates an additional active force $\mathrm{F}_{\mathrm{A}}^{\prime}$ which disturbs the balance between the applied and reactive forces. For idealised conditions the minimum critical length $\mathrm{L}_{\mathrm{cr}}$ should correspond to the half length of the fan-shaped structure. The length $\mathrm{L}_{\mathrm{cr}}$ in this approach is a function of the geometrical characteristics of the fault structure (fault thickness, angle of the initial block orientation, distance between blocks, etc), and elastic parameters of the face material.

\subsubsection{Fracture speed}

The maximum attainable rupture speed is a very important characteristic of the rupture process. To better understand the situation regarding shear fracture propagation, let us consider briefly a similar question for mode-I cracks. The theoretical limit for the mode-I crack speed $\mathrm{v}$ in a homogeneous solid is the Rayleigh speed $c_{R}$ which is approximately $90 \%$ of the shear wave speed $c_{S}$ in the same material (Freund, 1990; Broberg, 1999). This limit is obtained by assuming that an opening crack will propagate along a perfectly straight crack path in the homogeneous material. In special experiments where such conditions were artificially provided the predicted limiting speed was approached, in particular, in tests conducted on fabricated weak planes in a homogeneous material by bonding two identical plates of a brittle polymer (Washabaugh and Knauss, 1994). In real materials, however, the speed has never been observed to exceed $0.65 c_{R}$. Furthermore, in the overwhelming majority of cases the speed was only about $30-40 \%$ of $c_{R}$. The reason for that is the natural tendency for physical cracks to follow a wavy path and for microbranching, which results in a significant increase in microcrack population and, consequently, in the fracture energy (Ravi-Chandar and Knauss, 1984; Johnson, 1992; Gao, 1993).

For mode-II (shear) cracks the theory predicts the ability to propagate intersonically, that is at speeds between the compression wave speed $c_{P}$ and the shear wave speed $c_{S}$ (Freund, 1990; Brogerg, 1999). The theoretical models consider a crack propagating along a predetermined weak and straight-line crack path between two isotropic linear elastic solids. Experiments with brittle polyester resin, where similar conditions were modelled, proved the attainability of intersonic speed (Rosakis et al., 1999, 2006; Rosakis, 2002).

The question is whether these results, obtained for idealised conditions and homogeneous solids, can be used to verify the attainability of intersonic speed in natural heterogeneous rocks. By analogy with mode-I fracture discussed above we can suppose that it is unlikely, due to similar physical reasons: the natural tendency to follow a wavy crack path and unrestricted fracture thickness (unlike the experiments where a straight path and fault thickness of about 20 microns was predetermined). Existing evidence on the attainability of intersonic speed in rocks concerns earthquakes only. Earthquakes, however, are associated with another type of shear rupture - general faults - where the intersonic speed may result from an entirely different fracture mechanism. This question will be discussed later.

\subsubsection{Two-dimensional fracture development}

Shear fracture is a very complicated structural system that propagates two-dimensionally from a hypocentre forming a fracture plane. Existing models that aim to describe two-dimensional shear fracture propagation consider fractures of an extremely simplified version, without any internal structure. Our understanding of the important question of what kind of natural mechanisms provide two-dimensional shear fracture propagation is presented below.

Figure 6 shows a photograph (Ortlepp, 1997) of a lineated hackly surface of a shear fracture initiated in quartzite at a deep mine (depth about $2000 \mathrm{~m}$ ). Ortlepp points out that the lineated texture is not a result of shear traction as can often be observed on shear surfaces subjected to significant mutual displacement. The hackly surface contains footprints of rotating blocks that filled the shear rupture and have been washed away before the photograph was taken. These blocks are rock chips that look like fish scales. The footprints show that the blocks were arranged in an echelon of rows, and the photograph shows that the rows form curved lines. A white line in the picture reflects the orientation of rows in different areas of the plane. 


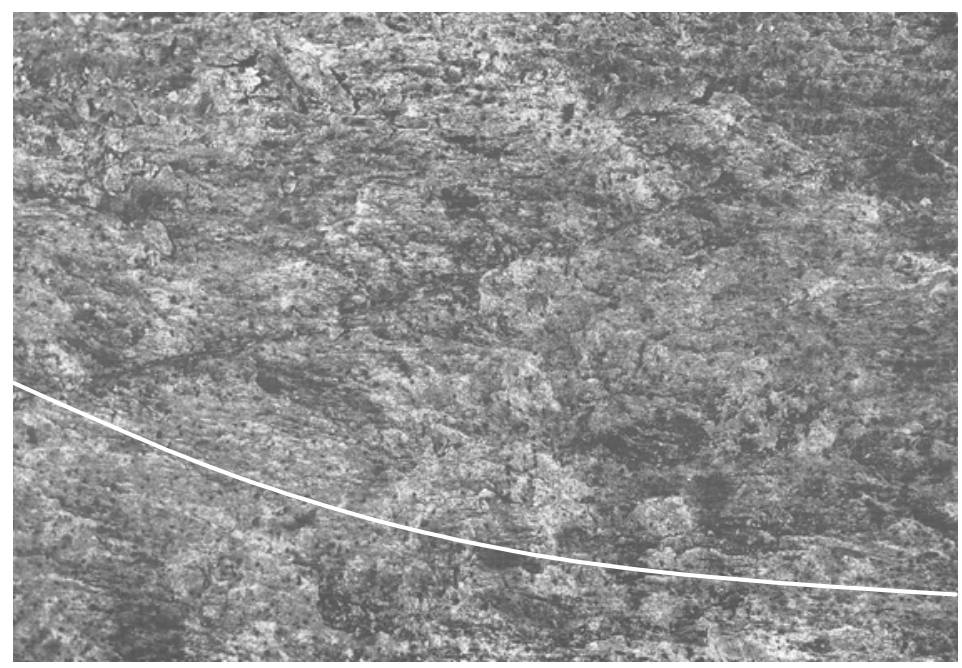

Figure 6 Hackly surface of a shear plane with footprints of rotating blocks (from Ortlepp, 1997)

Taking into account the observed structural features and the fan-shaped nature of the shear fracture propagation, the following two-dimensional model can be reconstructed. Figure 7 shows three stages of the fracture propagation. After the loss of stability at the hypocentre, the fracture, driven by the fan-shaped mechanism, propagates within a plane in all directions. Such propagation is possible due to segmentation of blocks (formation of scales). Dotted ellipses in the picture represent an echelon of rows comprising rock 'scales'. Within the elliptical front of the propagating fracture (shaded area) scales form the fan-shaped structure of the process zone, which propagates as a wave. Cross-sections of this fracture made in any direction should have a structure similar to that shown in Figure 4f. The distance (or speed) of propagation in different directions is proportional to shear stresses $\tau_{\varphi}$ acting in these directions, as illustrated in Figure 7. Due to the variation of $\tau_{\varphi}$ in different directions, the fracture acquires an ellipsoidal shape. Within a segment abc the mechanism of fracture formation must be different because in this segment the value of $\tau_{\varphi}$ is too small to provide adequate shear fracture development. We can suppose that in this area fracture development occurs in response to stress redistribution caused by propagation of other parts of the fracture.

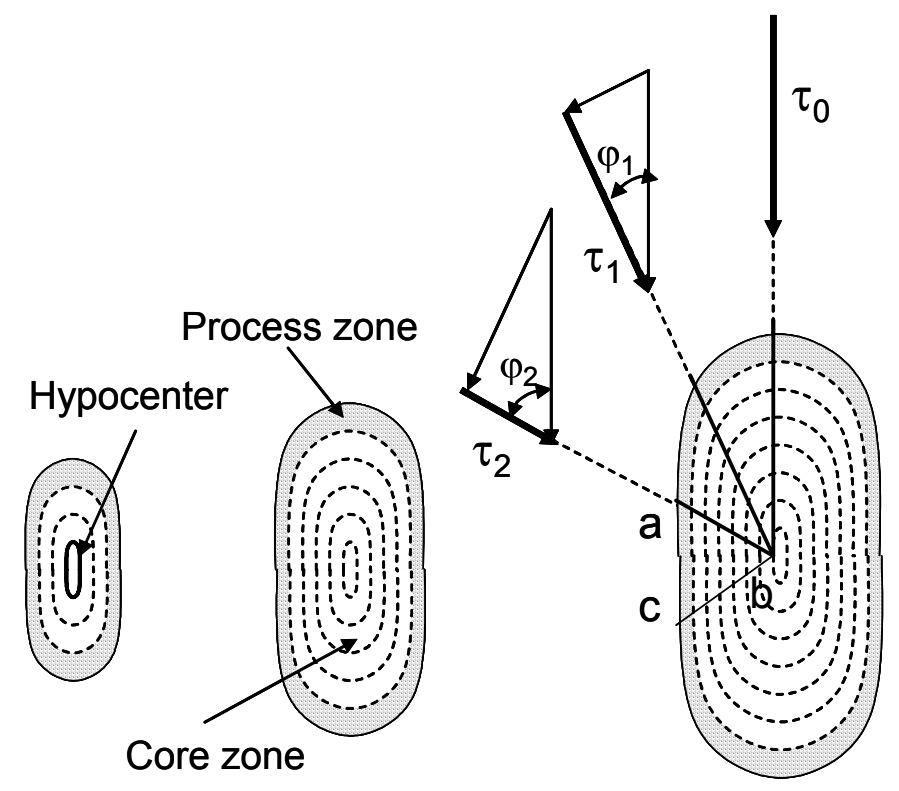

Figure 7 Model of two-dimensional shear fracture development (from Tarasov, 2007) 


\subsection{General fault}

\subsubsection{Fault segmentation (modern understanding)}

Segmentation in the form of discontinuities (overlapping primary faults) and branching is a fundamental feature of general faults (see examples in Figures 3b and 3c). Despite very intensive study of the nature of segmentation no consensus of opinion has been reached regarding the physical mechanisms responsible for this phenomenon (Clayton, 1966; Sharp and Clark, 1972; Segall and Pollard, 1983; Granier, 1985; Harris and Day, 1993; Vermilye and Scholz, 1999; Poliakov at al., 2002; Scholz, 2002). Examples of different mechanisms that have been proposed include:

- Segmentation as result of the linkage of pre-existing segments.

- Segments as an echelon of mode-I cracks involved in the structure of a general fault by analogy with tensile cracks in mode-II (or mode III) primary fractures.

- Segmentation as a result of separation of a continuous fault when it encounters stronger rock.

- Initiation of rupture on a branching fault due to stresses around a dynamically propagating rupture tip located off the main fault plane.

The interaction and linkage between an echelon of fault segments have also been studied extensively (Segall and Pollard, 1980; Sibson, 1986; Burgmann at al., 1994; Scholz, 2002). The role of jogs and overlapping parts of segmented faults in the faulting process was analysed, and it was established, in particular, that all types of jogs represent high strength barriers impeding static and dynamic fault motion (Segal and Pollard, 1980; Sibson, 1985; Harris and Day, 1993; Scholz, 2002).

\subsubsection{New approach - segmentation as a result of advanced fracture triggering}

The self-equilibrated fan-shaped mechanism acting in primary fractures facilitates fracture propagation due to neutralisation of shear resistance in the fracture tip. The core zone, however, with fully mobilised residual friction and a wavy crack path provides significant resistance to fracture displacement. In large faults where large displacements must be accommodated, nature has provided a special mechanism that facilitates this process, decreasing friction along the fault and neutralising the resistance caused by the wavy path. Segmentation is a key element of this mechanism.

In accordance with generally accepted concepts the formation of branches and overlaps occurs in the following sequences illustrated schematically in Figure 8a. The general fault comprising two segments ( 1 and 2) propagates from left to right. Bold arrows here represent developing fractures while the dotted lines correspond to potential fractures. In accordance with existing concepts the fracture process in segment- 2 can be initiated only after the fracture in segment-1 has reached segment-2. When segment-2 is initiated, segment-1 stops propagating further. The new stepped fracture (segment-2) in this case is merely the continuation of the previous one. According to this approach all steps between adjacent segments represent obstacles restricting fracture initiation in the next segment and the fault development as a whole.

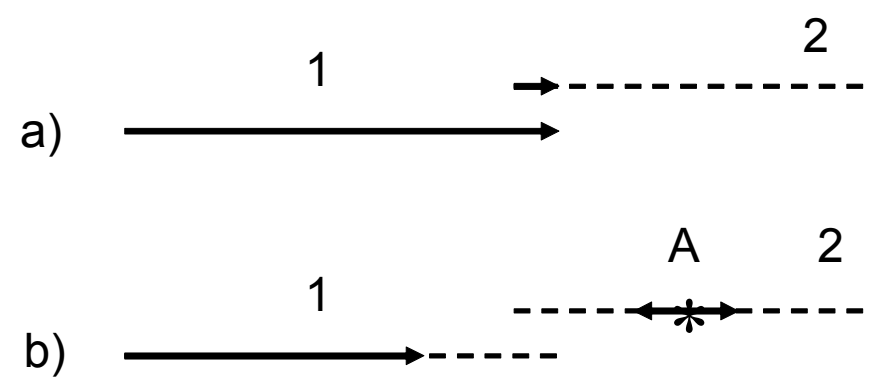

Figure 8 Features of the next segment initiation in accordance with a) common knowledge and b) new approach (from Tarasov, 2007) 
Figure $8 \mathrm{~b}$ illustrates a new mechanism, which is advanced fracture triggering. The propagating fracture-1 initiates a new fracture at point A due to the stress transfer at some distance ahead of the current fracture. The new fracture propagates bilaterally, both towards the current fracture and in the opposite direction. When the two approaching fractures meet they normally form an overlapping zone. Formation of the overlap is the result of interaction between the stress fields of the approaching fractures and can form even if the approaching fractures are initially propagating along the same plane. The following observations of fault structures support the idea of advanced triggering:

- Fault triggering is actively studied in seismology to understand initiation of new faults. Although the main focus of attention has been the analysis of situations where triggering of new ruptures occurs following some delay after the main event (e.g. Harris, 1998; Stain, 1999; King and Cocco, 2000; Ziv and Rubin, 2000; Scholz, 2002) there is evidence suggesting random heterogeneity in the faulting process where a number of sub-events are triggered practically simultaneously within the whole fault zone (Wyss and Brune, 1967; Andrews, 1980; Hanks and McGuire, 1981).

- Vermilye and Scholz (1999) pointed out that results of structural analysis conducted by them for two neighbouring segments could be interpreted as evidence of independent nucleation and linkage of initially isolated fault segments propagating towards each other. However, because this fact is in conflict with the common approach, they suggested an alternative mechanism for this fault segmentation.

- Results of analysis of the fault structure in zones linking segments also support the idea that the linked segments propagated in opposing directions. This question is discussed further below.

\subsubsection{Linkage of stepped segments}

Two photographs in Figure 9 show junctions at different degree of their development. The diagrams between the photographs present each situation schematically. In the picture, the propagating segments are shown by bold arrows while open arrows indicate the directions of shear. The left hand photograph clearly demonstrates that the two approaching segments are represented by primary fractures. Before meeting, the fractures deflected slightly due to interaction of their stress fields and have then propagated further forming an overlapping zone. When the overlap reaches some critical length the overlapping zone has separated into rotating blocks by the creation of tensile cracks resulting from shear along the overlapping zone. The right hand photograph shows that an intensive echelon of blocks was eventually formed after further propagation of the segments of primary fractures.

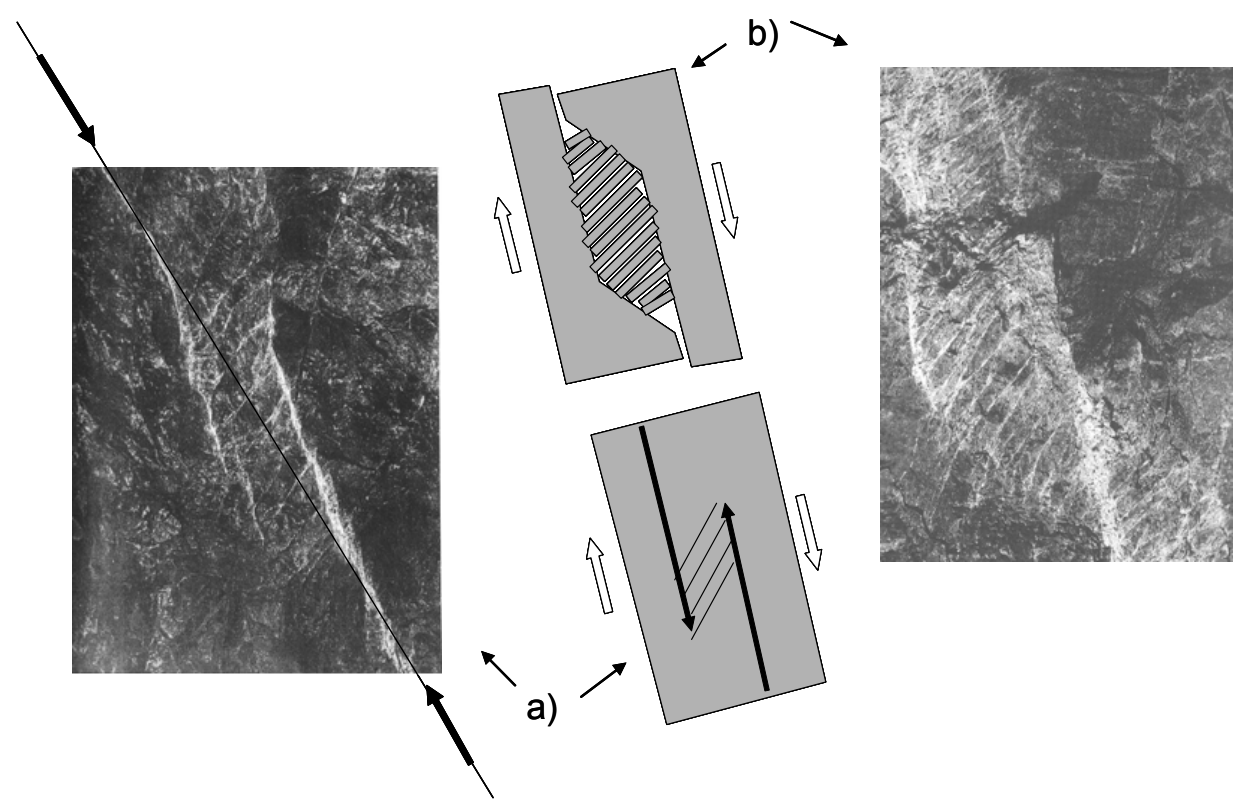

Figure 9 Linkage of stepped segments propagating in opposite directions (from Tarasov, 2007, photographs from Ortlepp, 1997) 
Hence, linkage zones between segments represent special joining shear fractures comprising an echelon of rotating blocks, as is typical for all types of shear fractures. Unlike primary shear fractures, which propagate due to the fan-shaped mechanism, the joining fractures are formed simultaneously due to shear within the overlap zone. In contrast with primary fractures, the joining fractures are relatively short and thick. Their function is to facilitate displacement of the general fault. The joining fractures create outward forces perpendicular to the fault axis, due to rotation of the blocks, thus unloading adjacent parts of the segments and decreasing friction in them. Open cracks along the segments of primary fracture can be seen in the right hand photograph.

Figure 10 shows three possible types of linkage of stepped segments propagating towards each other. In all cases the segments are combined in one fault by joining fractures within the linkage zone. All of these fractures comprise block structures where behaviour during displacement of the fault is consistent with the frictionless concept. The existence of joining fractures in the general fault facilitates accommodation of large displacements and decreases the fault resistance to shear. This contrasts with the traditional point of view according to which jogs and other forms of discontinuity represent high resistance barriers impeding static and dynamic fault motion.

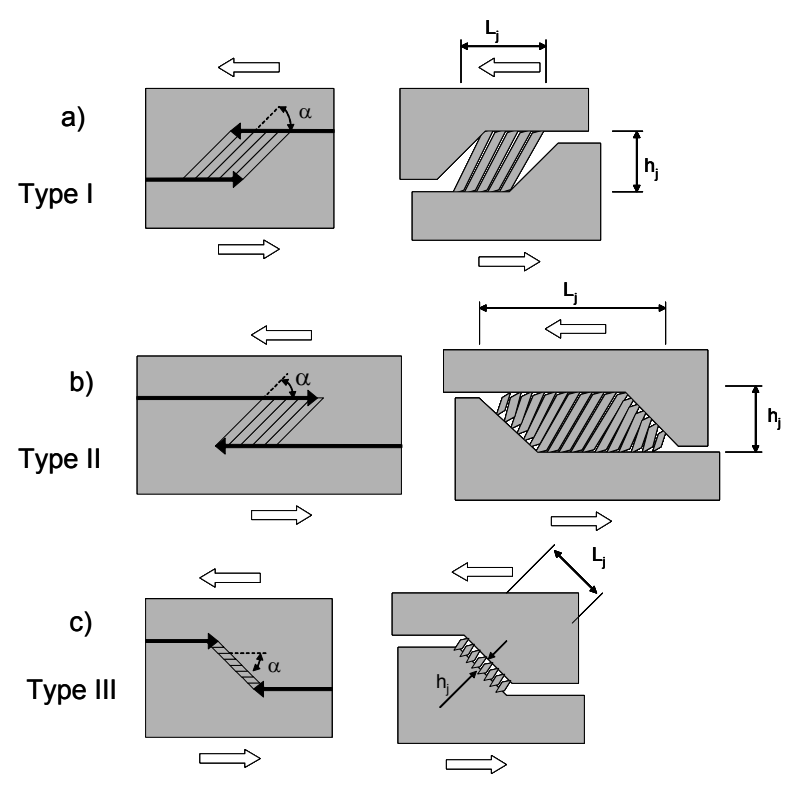

Figure 10 Three possible types of the linkage of stepped segments propagating in opposite directions (from Tarasov, 2007)

\subsubsection{Jump-like fault propagation}

Advanced triggering of new faults allows understanding the formation sequence of general faults with very complicated structure. Figure 11 presents seven stages of development of the fault, the photograph of which is shown in Figure 3b. A reduced copy of this photograph is located in the top right corner in Figure 11. The fault propagates upwards from the bottom and involves a number of primary fractures with significantly developed overlap zones. Contours of this fault are shown in the picture by dotted lines with bold arrows representing primary fractures, open arrows indicating the direction of shear and shaded areas representing joining fractures with a corresponding block structure. The orientation of rotating blocks of the fault structure relative to the fault axis is approximately the same in the diagram and in the photograph. Asterisks indicate centres of initiation of advanced triggered fractures.

At stage-I a dynamically propagating primary fracture triggers an advanced fracture, the further development of which is shown at stage-II. This new fracture (as well as all further triggered fractures) propagates bilaterally towards the current fracture and in the opposite direction. This fracture in turn triggers the next advanced fracture shown at stage-III. At this stage the length of overlapping zone between the two bottom fractures has reached the critical value and the first joining fracture is created. The process of creating the joining fracture involves dynamic shear accompanied by jump-like displacement within this zone and stress 
relaxation in the surrounding area. Further fault development occurs through repetition of similar stages. Both processes governing the general fault development - advanced triggering and the formation of joining fractures - have a jump-like character. Hence, jump-like propagation for general faults and wave-like (fanshaped wave) propagation for primary fractures are two different natural forms of shear fracture development.

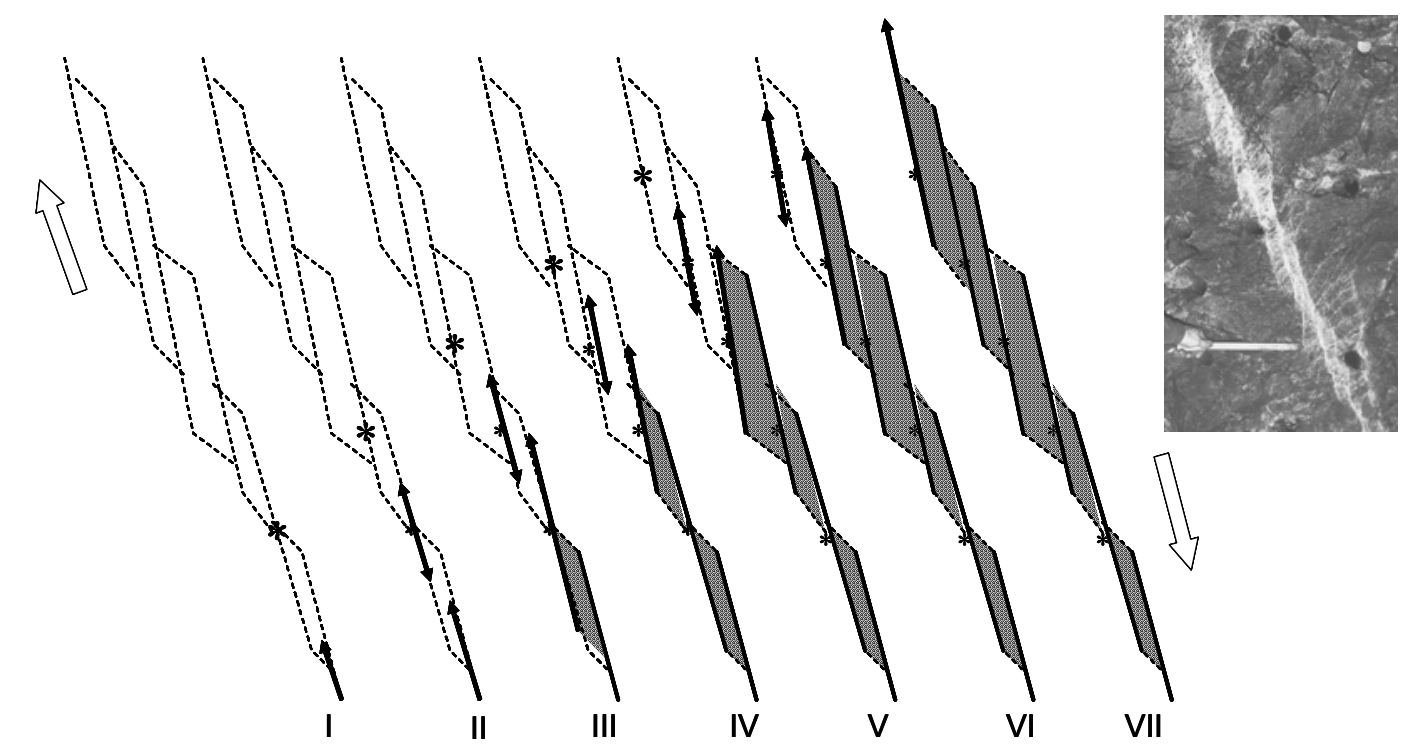

Figure 11 Jump-like fault propagation due to advanced rupture triggering

\subsubsection{Speed trebling mechanism}

The average rupture speeds for most shallow crustal earthquakes range from 0.75 to $0.95 \mathrm{cR}$ where $\mathrm{cR}$ is the average Rayleigh wave speed in the surrounding crustal rock mass (Kanamory and Brodsky, 2000). However, considerable evidence of intersonic rupture speeds have been reported (Archuleta, 1982; Olsen et at., 1997; Ellsworth and Celebi, 1999; Hernandez et al., 1999). It is important to emphasise that earthquake ruptures represent general faults in our classification. Rock damage associated with general faults compared with primary fractures is significantly greater. In this regard it appears paradoxical that intersonic speed is attainable for earthquake ruptures and has never been reported for primary fractures in rocks. This paradox can be explained if we analyse the mechanism of advanced triggering in more detail. The mechanism leads to a propagation speed for general faults that is three times that in primary fractures. Figure 12 illustrates this.

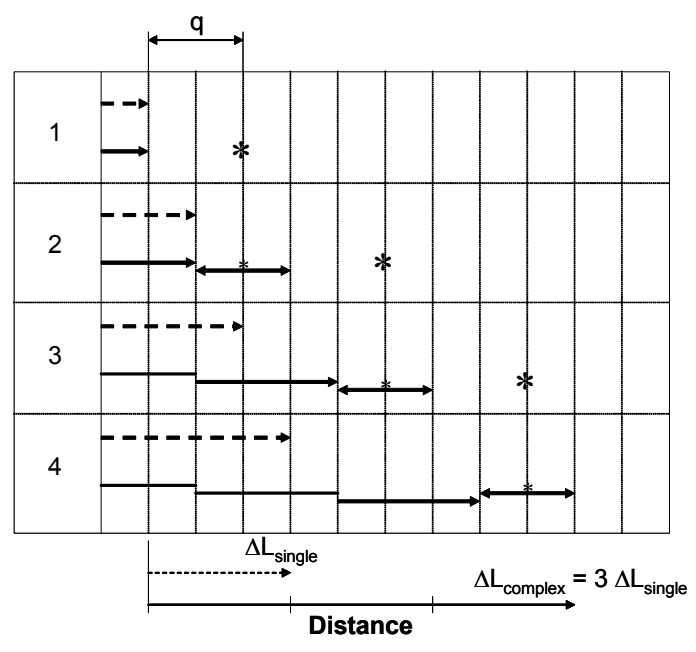

Figure 12 Illustration of the speed trebling mechanism (from Tarasov, 2007) 
The figure shows four stages of propagation of two different faults, which propagate from left to right (the horizontal axis representing distance). The first fault shown by dotted arrows develops as a primary fracture. Solid arrows represent the general fault propagating in accordance with the advanced triggering mechanism, with centres of triggered segments shown by asterisks. It is assumed that the speed of propagation of primary fractures in the general fault and in the first fault is the same. The total growth for the two modes of fault propagation, over the four stages considered, is indicated at the bottom of the figure, showing that the growth provided by the new mechanism is three times that for the conventional mode $\left(\Delta L_{\text {complex }}=3 \Delta L_{\text {single }}\right)$. In this example, the distance q between the fault edge and each new nucleation centre in the next segment was kept the same. It should be noted that the efficiency of the trebling mechanism does not depend on the value of q. However, we can expect that with the fault growth the distance q should increase due to increasing influence of the growing fault on the stress regime in the surrounding rock mass.

Before making a final conclusion about the general fault speed, it is important to mention the following result of observations. It was found by Wyss and Brune (1967) that the 1964 Alaska earthquake, propagated from east to west at a speed near the shear velocity, and consisted of a sequence of recognisable sub-events. The observed feature confirms that the nature of general fault propagation involves advanced triggering and the intersonic speed achievement is a result of the trebling effect. Hence, to reach a speed of $5 \mathrm{~km} / \mathrm{s}$ the speed of primary fractures should be about $1.7 \mathrm{~km} / \mathrm{s}$. The result obtained looks realistic and explains the paradoxical combination of intersonic speed and severe damage of the rock mass within the fault zone which have been observed in earthquake ruptures.

\subsubsection{Two-dimensional model}

Figure 13a illustrates the development of a general fault, initiated from a hypocentre shown by the asterisk. Due to stress transfer a set of new faults can be triggered in the vicinity of the first fault. Once that occurs, the influence of the combined fault on the surrounding rock mass increases, which can trigger new faults at greater distance. It should be noted that the triggered segments develop on the same principle of advanced triggering creating a self-similar structural hierarchy (see Figure 13b). This mechanism is therefore consistent with the fractal structure observed in natural faults at all scales (Scholz, 2002). Figure 13 shows symmetric location of segments in the general fault, although in reality this picture may be very chaotic. However, the main concept of its formation stays the same: the larger the fault grows, the greater is the chance to trigger new faults at greater distance; also the greater the distance the larger is the new activated segment. So, dimensions of segments increase with fault development from hypocentre to periphery. Although chaotic in detail the fault structure in general should be similar to that presented in Figure 13. When such complex fault reaches an open surface (axes x-x or y-y in Figure 13) its cross-section can be seen as an echelon of identical segments as shown in Figures $3 b$ and $3 c$.

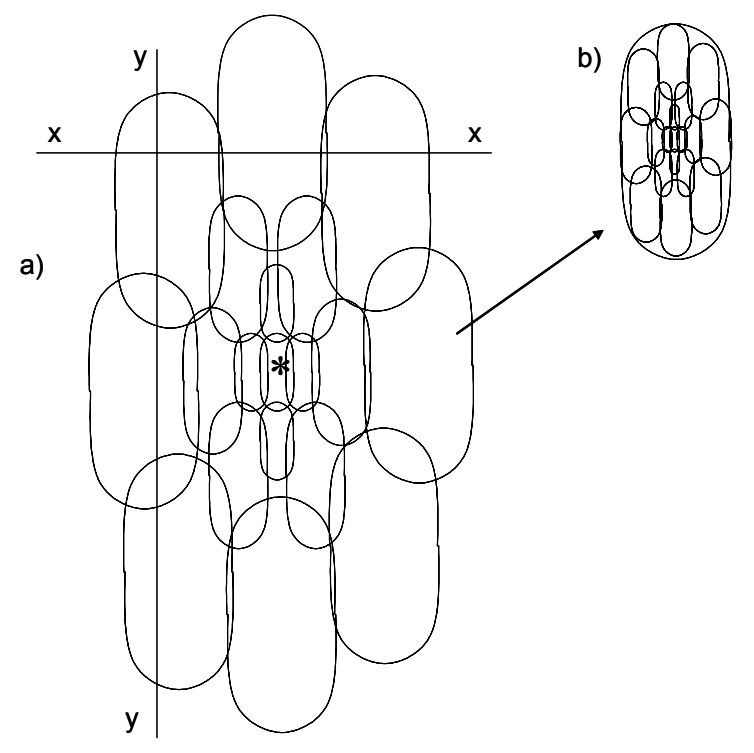

Figure 13 Two-dimensional model of the general fault formation (from Tarasov, 2007) 
It should be emphasised again that areas of linkage between segments where joining shear fractures are formed facilitate fault displacement and can significantly reduce the fault strength due to activation of the frictionless mechanism in these fractures. The larger is the proportion of linkage areas in the total fault plane the greater will be the influence of the frictionless mechanism on the fault resistance. Pictures in Figure 13 show that in some zones of the fault three or even four segments can intersect creating very complicated junctions. It should be noted also that the schema in Figure 13 illustrates the direct sequence of the general fault propagation, which is characterised by an increase in the segment size from the hypocentre to periphery. However, it is clear (and field observations verify this, Scholz, 2002) that the maximum fault displacement will be accumulated in the central part of the fault. This means that with further fault propagation additional fracture processes will be activated leading to significant and increasing damage of the central part of the fault.

\subsubsection{Fault reactivation}

The specific structure of shear fractures associated with an echelon of rotating blocks plays a very important role not only in the rupture process but also in the subsequent life of the fault and can be a key element in the reactivation of existing faults. In accordance with the frictionless concept (see Figure 2) the block structure resistance is a function of the block orientation relative to the fault axis. At some stage of the block rotation this resistance can become negative due to creation of active forces. The thickness of real faults is generally very irregular, as illustrated schematically in Figure 14. The diagram shows that at a given fault displacement $\mathrm{d}$, the angle $\beta$ of block rotation will be different, depending on the fault thickness. So, during stable tectonic fault displacement the block structure within some area of the fault can be brought into unstable conditions due to active forces (following rotation of the blocks beyond the normal to the fault) which can initiate instability of the whole fault. The process of initiation of the instability in such cases is very unpredictable.

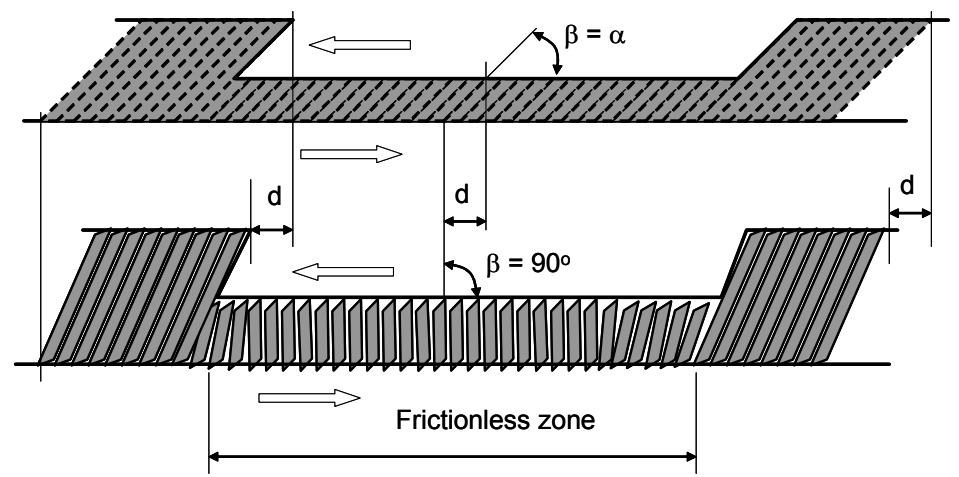

Figure 14 Features of the fault structure behaviour due to irregular fault thickness (from Tarasov and Randolph, 2007)

\section{$4 \quad$ Mining induced shear rupture}

Modern earthquake seismology considers the development of faults in the earth's crust as a process taking place in a significantly fractured crustal structure where the strength and behaviour of rock is determined by a friction law (Nur, 1978; Tse and Rice, 1986; Scholz 2002). It is considered that the crust is riddled with small faults of varying orientations, the reactivation of which depends on the stress level and a proper orientation of these faults. This approach to the fault process bypasses a key question regarding what mechanism can provide shear fracture development in pristine hard rocks at great depth. The importance of this question is based on the fact that all existing faults in the crust were initially formed in pristine rocks, the strength of which was significantly higher than their frictional strength. Undoubtedly, the development of new faults in pristine rocks within the crust takes place nowadays, and indeed experience in deep mining confirms this.

Shear rupture rockbursts (as well as earthquakes) are the attribute of great depth. They normally take place below some critical depth and increase their violence and activity with depth. Another very important feature of shear rupture rockbursts is the nucleation within the rock space at a point some considerable distance 
away from the surface of an opening, unlike other types of rockbursts (e.g. strain-burst, buckling, face crush) which occur right at the surface (Ortlepp, 2000). Abnormal properties of hard rocks induced by high confining pressure (as discussed previously) explain such features. Hard rocks exhibit these properties of extreme brittleness and very low post-failure strength $\left(\tau_{\mathrm{p}-\mathrm{f}}\right)$ at confining pressure above some critical level.

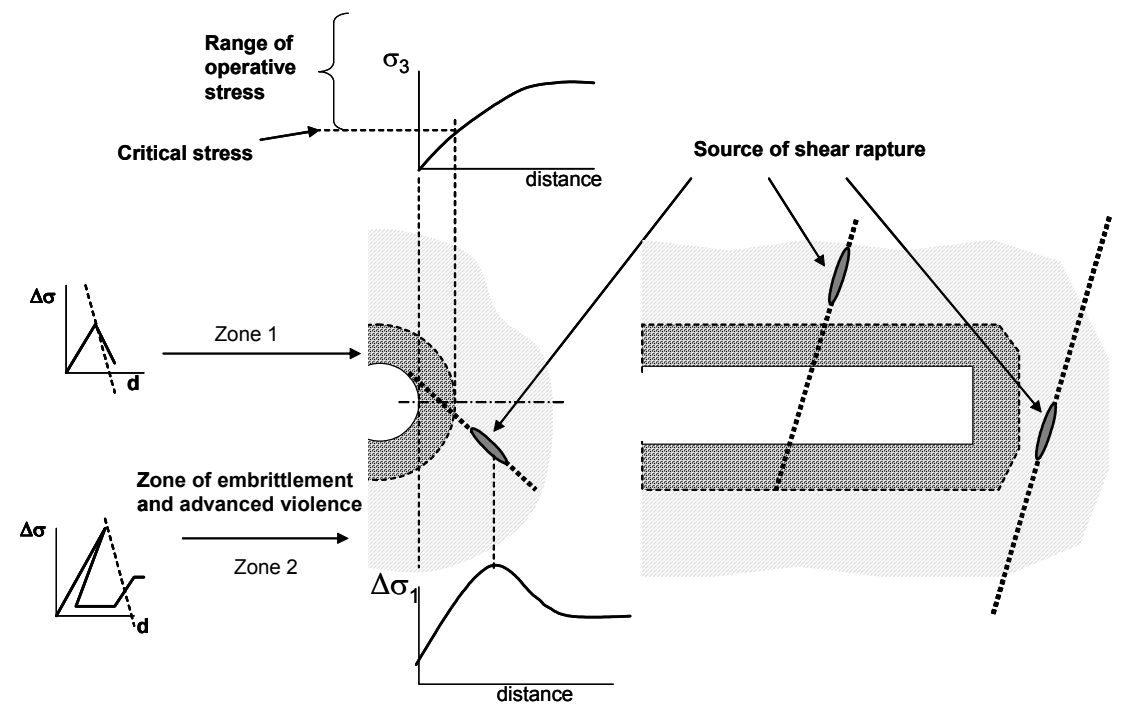

Figure 15 Features of shear rupture initiation around an opening (from Tarasov and Randolph, 2007)

The opening presented in Figure 15 is located below the critical depth where the abnormal rock properties are activated. The graph shown at the top of the figure characterises the distribution of the minor stress $\sigma_{3}$ around the opening. A range of minor stress located above the critical stress represents an operative range of stress where the frictionless mechanism is applicable. A graph at the bottom of the figure symbolises the distribution of the differential stress $\Delta \sigma_{1}$ around the opening. A maximum of the $\Delta \sigma_{1}$ stress concentration is located at some distance from the open surface.

In the rock mass surrounding the opening, two zones of different rock behaviour can be distinguished. Zone 1 is characterised by a level of minor stress below the operative range. Rocks in these zones exhibit normal (well known) behaviour. A possible relation between the post-peak rock stiffness and loading stiffness for this zone is illustrated by a graph on the left of the figure, which characterises the situation in this zone as stable. The situation in zone 2, by contrast, is abnormal and unstable despite the fact that the loading stiffness here is the same. Rocks in this zone have extreme brittleness due to the frictionless mechanism. A new fracture can be initiated at any point within this zone where the level of shear stress, caused by the stress concentration, exceeds the rock strength. The rupture development will be violent. The direction, attitude and extent of this rupture are determined by the prevailing stress field. By analogy, tectonic stresses taking place in the earth's crust can also initiate new shear ruptures in pristine rocks at great depth in the form of earthquakes.

\section{Conclusions}

This paper proposes a new 'frictionless concept' which explains a number of paradoxes and unexplained phenomena associated with the shear rupture process. It is shown, in particular, that hard rocks at high confining pressure acquire specific properties which distinguish them markedly from common rock behaviour - they become extremely brittle and lose shear resistance within a certain range of the shear rupture displacement. The combination of these properties increases instability with depth and makes rupture abnormally violent. These hard rock features are caused by the intrinsic nature of the fault structure which is an echelon of blocks operating as hinges, essentially eliminating friction at high confining pressure.

The frictionless concept allows the process of shear fracture development to be viewed from a new point of view. A simple but well-founded classification of shear fractures is used in the paper, namely: i) primary fractures and ii) general faults. It is shown that despite the similarity in their structures, each of which is 
represented by an echelon of rotating blocks, the development of these two forms of fractures is drastically different. Primary fractures propagate in a wave-like manner due to a fan-shaped self-equilibrated mechanism created on the basis of rotating blocks. General faults propagate in a jump-like manner forming a cascade of segments and junction zones due to advanced triggering mechanism. Features of the both mechanisms have been analysed in the paper allowing a number of paradoxical observations associated with shear fracture development to be explained. Two-dimensional models for both types of fracture have also been presented.

\section{Acknowledgements}

This work was supported during a number of years by the Australian Special Research Centre for Offshore Foundation Systems (COFS). This support is gratefully acknowledged.

\section{References}

Andrews, D. (1976) Rupture velocity of plane strain shear cracks. J. Geophys, Res. 81, pp. 5679-5687.

Andrews, D. (1980) A stochastic fault model, static case. J. Geophys. Res. 85, pp. 3867-3887.

Archuleta, R. (1982) Analysis of near source static and dynamic measurements from the 1979 Imperial Valley earthquake. Bull. Seismol. Soc. Am., Vol. 72, pp. 1927-1956.

Ashby, M.F. and Sammis, C.G. (1990) The damage mechanics of brittle solids in compression, Pure Appl. Geophys., Vol. 133, pp. 489-521.

Ben-Zion, Y. and Andrews, D.J. (1998) Properties and implications of dynamic rupture along a material interface. Bull. Seismol. Soc. Am., Vol. 88, pp. 1085-1094.

Broberg, K.B. (1999) Cracks and Fracture, London, Academic.

Burgmann, R., Pollard, D.D. and Martel, S.J. (1994) Slip distributions on faults: effects of stress gradients, inelastic deformation, heterogeneous host-rock stiffness, and fault interaction, J. Struct. Geol. 16, pp. 1675-1690.

Chester, F.M., Evans, J.P. and Biegel, R.L. (1993) Internal structure and weakening mechanisms of the San Andreas Fault, J. Geophys. Res., Vol. 98, pp. 771-786.

Clayton, L. (1966) Tectonic depressions along the Hase fault, a transcurrent fault in north Canterbury, New Zealand, New Zealand J. Geol. Geophys. Vol. 9, pp. 94-104.

Das, S. (1985) Application of dynamic shear crack models to the study of the earthquake faulting process. Int. J. Fract., Vol. 27, pp. 263-276.

Domowska, R. and Rice, J.R. (1986) Continuum theories in solid earth physics, Amsterdam: Elsevier, pp.1881-1902.

Ellsworth, W.L. and Celebi, M. (1999) Near field displacement time histories of the M7.4 Kocaeli (Izmit) Turkey earthquake of August 17, 1999. The American Geophysical Union Fall Meeting, Vol. 80 (Washington D.C: American Geophysical Union), p. F648.

Freund, L.B. (1990) Dynamic fracture mechanics, Cambridge, Cambridge University Press.

Gao, H. (1993) Surface roughening and branching instabilities in dynamic fracture. J. Mech. Phys. Solids., Vol. 41, N3, pp. 457-486.

Granier, T. (1985) Origin, damping and pattern of development of faults in granite, Tectonics, Vol. 4, pp. 721-737.

Hanks, T. and McGuire, R. (1981) The character of high-frequency strong ground motion. Bull. Seismol. Soc. Am., Vol. 71, pp. 2071-2095.

Harris, R.A. and Day, S.M. (1993) Dynamics of fault interaction: parallel strike-slip faults. J. Geophys. Res., Vol. 98, pp. 4461-4472.

Harris, R.A. (1998) Introduction to special section: Stress triggers, stress shadows, and implications for seismic hazard. J. Geophys. Res.-Solid Earth, Vol. 103, pp. 24347-24358.

Heaton, T.H. (1990) Evidence for and implications of self-healing pulses of slip in earthquake rupture. Physics of the Earth and Planetary Interiors, Vol. 64, pp. 1-20.

Hernandez, B., Cotton, F. and Campillo, M. (1999) Contribution of Radar interferometry to a two-step inversion of the kinematic process of the 1992 Landers earthquake. J. Geophys. Res. 104, pp. 13083-13099.

Hickman, S.H. (1991) Stress in the lithosphere and the strength of active faults, Rev. Geophys, Vol. 29, pp. 759-775.

Ida, Y. (1982) Stress concentration and unsteady propagation of longitudinal shear cracks, J. Geophys. Res., Vol. 77, pp. 3796-3850.

Johnson, E. (1992) Process region changes for rapidly propagating cracks. Int. J. Fract., Vol. 55, pp. 47-63.

Kanamori, H. and Brodsky, E. (2001) The physics of earthquakes, Phys. Today, Vol. 54, pp. 34-40.

King, G.C.P and Sammis, C.G. (1992) The mechanisms of finite brittle strain, PAGEOPH, 138, pp. 611-639.

King, G.C.P. and Cocco, M. (2000) Fault interaction by elastic stress changes; new clues from earthquake sequences. Advances in Geophys, Vol. 44, pp. 1-38.

Lockner, D.A., Byerlee, J.D., Kuksenko, V., Ponomarev, A. and Sidorin, A. (1991) Quasi-static fault growth and shear fracture energy in granite Nature, Vol. 350, pp. 3942. 
Mandel, G. (2000) Faulting in brittle rocks. Springer-Verlag Berlin Heidelberg.

McKenzie, D. and Brune, N. (1972) Melting on fault planes during large earthquakes, Geophys. J. R. Astr. Soc., Vol. 29, pp. 65-78.

Moore, D.E., Summers, R. and Byerlee, J.D. (1990) Faults, fractures and other deformation features produced during loading of granite in triaxial equipment. U.S. Geol. Surv. Open File Rep., pp. 90-349.

Moore, D.E. and Lockner, D.A. (1995) The role of microcracking in shear-fracture propagation in granite, J. Struct. Geol. 17, pp. 95-114.

Nur, A. (1978) Nonuniform friction as a basis for earthquake mechanics. Pageoph, Vol. 116, pp. 964-989.

Olsen, K.B., Madariaga, R. and Archuleta, R.J. (1997) Three-dimensional dynamic simulation of the 1992 Landers earthquake. Science, 278, 834 .

Ortlepp, W.D. (1997) Rock fracture and rockbursts. The South African Institute of mining and metallurgy, Johannesburg.

Ortlepp, W.D. (2000) Observation of mining-induced faults in an intact rock mass at depth. Int. J. Rock Mech. Min. Sc., Vol. 37, pp. 423-436.

Peng, S. and Johnson, A.M. (1972) Crack growth and faulting in cylindrical specimens of Chelmsford granite. Int. J. Rock Mech. Min. Sci. Vol. 9, pp. 37-86.

Poliakov, A.N.B., Domowska, R. and Rice, J.R. (2002) Dynamic shear rupture interactions with fault bends and offaxis secondary faulting, J. Geophys. Res. 107, No. B11, 2295, doi 10.1029/2001JB000572, ESE 6-1-6-18.

Ravi-Chandar, K. and Knauss, W.G. (1984) An experimentql investigation into dynamic fracture: I. Crack initiation and arrest. Int. J. Fract., Vol. 25, pp. 247-262.

Reches, Z. and Lockner, D.A. (1994) Nucleation and growth of faults in brittle rocks. J. Geophys. Res. Vol. 99, No. B9, pp. 18159-18173.

Rice, J.R. (2001) New perspectives on crack and fault dynamics in Mechanics for a New Millennium: The $20^{\text {th }}$ International congress of theoretical and applied mechanics, H. Aref and J.W. Phillips (eds), Dordrecht: Kluwer, p. 23.

Rosakis, A.J., Samudrala, O. and Coker, D. (1999) Cracks faster than the shear wave speed. Science, Vol. 284, pp. $1337-1340$.

Rosakis, A.J. (2002) Intersonic shear cracks and fault ruptures. Advances in Physics, Vol. 51, No. 4, pp. 1189-1257.

Rosakis, A.J. (2006) Laboratory earthquakes. Int. J. Fracture, Vol. 138, pp. 211-218.

Scholz, C.H. (2002) The mechanics of earthquakes and faulting. Cambridge University Press.

Segall, P. and Pollard, D.D. (1980) The mechanics of discontinuous faults, J. Geophys. Res., Vol. 85, pp. 4337-4250.

Segall, P. and Pollard, D.D. (1983) Nucleation and growth of strike-slip faults in granite, J. Geoph. Res., Vol. 88, pp. 555-68.

Sharp, R.V. and Clark, M.M. (1972) Geologic evidence of previous faulting near the 1968 rupture on the Coyote Creed fault. U.S. Geol. Surv. Proof. Pap., Vol. 787, pp. 131-140.

Sibson, R.H. (1980) Power dissipation and stress levels on faults in the upper crust. J. Geophys. Res., Vol. 85, pp. 62396247.

Sibson, R.H. (1985) Stopping of earthquake ruptures at dilatational jogs. Nature, 316, pp. 248-251.

Sibson, R.H. (1986) Rupture interaction with fault jogs, Earthquake source mechanisms, S. Das, J. Boatwright, and C.H. Scholz (eds), American Geophysical Union, Washington.

Stain, R.S. (1999) The role of stress transfer in earthquake occurrence. Nature, Vol. 402, pp. 605-609.

Tarasov, B.G. (2007) Intersonic shear rupture mechanism (submitted to Int. J. Rock Mechanics 12.02.2007).

Tarasov, B.G. and Dyskin, A.V. (2005) The phenomenon of anomalous rock embrittlement. $6^{\text {th }}$ International Symposium on Rockburst and Seismicity in Mines Proceedings, Australia, pp. 311-317.

Tarasov, B.G. and Randolph, M.F. (2007) Frictionless shear at great depth and other paradoxes of hard rocks. Int. J. Rock Mechanics (in press).

Tse, S. and Rice, J. (1986) Crustal earthquake instability in relation to the depth variation of frictional slip properties. J. Geophys. Res. 91, pp. 9452-9472.

Vermilye, J.M. and Scholz, C.H. (1999) Fault propagation and segmentation: insight from the microstructural examination of a small fault. J. Struct. Geol., Vol. 21, pp. 1623-1636.

Washabaugh, P.D., and Knauss, W.G. (1994) A reconciliation of dynamic crack velocity and Rayleigh wave speed in isotropic brittle solids. Int. J. Fract., Vol. 65, pp. 97-114.

Weertman, J. (1980) Unstable slippage across a fault that separates elastic media of different elastic constants. J. Geophys. Res., Vol. 85, p. 1455.

Wyss, M. and Brune, J. (1967) The Alaska earthquake of 28 March 1964: A complex multiple rupture. Bull. Seismol. Soc. Am., Vol. 57, pp. 1017-1023.

Ziv, A. and Rubin, A.M. (2000) Static stress transfer and earthquake triggering: no lower threshold in sight, J. Geophys. Res., 105, pp. 13631-13642. 